\title{
Problem-based learning and action learning in Ugandan universities
}

\author{
Jacinta Bwegyeme ${ }^{1}$, , John .C. Munene ${ }^{2}$, James Kagaari ${ }^{3}$, Geoffrey Bakunda ${ }^{4}$
}

(C) Uganda Martyrs University

\begin{abstract}
The purpose of the study was to compare the action learning approach with the traditional didactic learning and establish the relationship between problem-based learning and action learning. We employed a quasi-experiment where the Marquardt Action Learning model was combined with the constructivist theories of learning. The quasi experiment was composed of three groups, namely the treatment group (action learning group), the traditional group and the control group. To stimulate participant thought and reflection, a community of practice environment was created and just-in-time classes were conducted, based on the constructive theories of learning. Although the study involved various constructivist theories, the article concentrates on problem-based learning; hence, it is quiet about other constructivist theories. The results indicate significant differences between the action learning and traditional didactic learning. Furthermore, a significant relationship between problem-based learning and action learning was established. The robust strength of reflective practice and self-directed learning in the prediction of action learning is also highlighted. The findings can be utilised to design future training programmes in universities and other workplaces in order to equip workers with reflective practice and self-directed learning skills that are vital in solving workplace problems.
\end{abstract}

Key words $\cdot$ Problem-based learning $\cdot$ Action learning $\cdot$ Community of practice

\section{Introduction}

The existing Ugandan University Education has been commended for delivering relevant comprehensive theoretical content that develops the intellectual abilities of students (Bigabwenkya, 2013). However, the curriculum ignores problem-based learning and action learning approaches yet these are more practical and rational approaches for analysing complex issues and generating realistic solutions at a workplace. The University curriculum is based on lower level learning objectives that focus on recall while disregarding higher-level action oriented objectives such as application, evaluation and adaptation (Anderson and Krathwohl, 2001). Bigabwenkya's (2013) study of Theory and Practice Integration in Public University

\footnotetext{
${ }^{1}$ Uganda Martyrs University, *Corresponding author: jbwegyeme@umu.ac.ug

${ }^{2}$ Makerere University Business School

${ }^{3}$ Kyambogo University

${ }^{4}$ Makerere University Business School
} 
Education, established that the University curriculum was more theoretical and less practical. This is in agreement with Nabayego and Itaaga (2014) who observed that the Ugandan University Education ignores active learning and instead promotes lecturing and memorising facts, which fall short of preparing learners for workplace demands. It is clear from literature that most of the trainings done in organisations never address real issues because they are theoretical and do not address the skills' gap (Silverman, 2012; Maister, 2014; Boshyk, 2002). At the same time, the education of our graduates is theoretical, which leaves the graduate unprepared for the workplace. The purpose of this study, therefore, is to contribute to literature by examining the relationship between Problem-Based Learning (PBL) and action learning in Ugandan Universities in order to suggest an appropriate active learning approach that equips workers/students with appropriate skills for the workplace. Using quantitative data, the study also underscores the power of the action learning approach in learning and problem solving compared to the traditional methods of training.

PBL has been defined as a progressive active learning and learner centred approach where unstructured problems are used as the starting point and anchor for the learning process (Hung, Jonassen and Liu, 2006). Problem-based learning has been commended for problem solving and transference of learning to the workplace (Alvarstein and Johannesen, 2001). The review of theoretical literature and empirical research indicate that problem-based learning principles are vital for problem solving (Hung, Jonassen and Liu, 2006).

A lot of empirical research has been carried out relating PBL to problem solving skills. For example, Gallagher, Stepien and Rosenthal (1992) and Lohman and Finkelstein (2000) established that learners who are taught using the problem-based learning methods showed a significant increase in the use of the problem finding steps and improved their transfer of problem solving skills to the real world of practice. Kiguli-Malwadde, Businge and Mubuuke (2009) established that PBL was a gateway to the acquisition of key generic skills like problem-solving and self-directed learning.

The central argument in PBL theory is that problems are the anchors for learning. Therefore, we can confidently relate PBL to action learning because action learning is the learning that takes place during the problem solving process (McGill and Brockbank, 2004).

\section{Action learning}

Action learning is a dynamic process that involves a small group of people solving real problems while focusing on individual and organisational learning (Marquardt, 2004). In an organisation, individuals learn with and from one another while diagnosing and solving real problems (O'Neil and Marsick, 2007; Trehan and Pedler, 2011). Hence, the action learning approach empowers the learners that discuss similar problems within a similar working context. According to Skills for Care (2014), action learning takes challenges of professional work as the vehicles for learning. Revans 
(1980) designed action learning for complex and wicked issues that defy rational analysis. Several scholars, various organisations and individuals recognise the importance of action learning in solving real problems and learning as the problem is being solved (O'Neil and Marsick, 2007; Bwegyeme and Munene, 2015).

Universities in Uganda have experienced challenges such as resource constraints, inadequate staffing, deteriorating infrastructure and other management inefficiencies (Ddumba Sentamu, 2013), yet university education remains the uppermost level of higher education. Literature indicates that challenges affecting university education in Uganda are continuously transmuting; therefore, complex. Bwegyeme and Munene (2015) established that the problems affecting the universities as indicated above directly impinge on the performance of the administrators in the department of the academic registrar. The problems in universities that affect the administrators affect the academic staff as well. However, this study focuses on administrators, because review of university documents indicate that little attention has been paid to the training of administrators (Tibarimbasa, 2010; Makerere University Training Policy, October 2009) yet the administrators that handle the complex problems that emerged with expansion. Consequently, the study intended to devise practical solutions to the Academic Registrar's department by equipping the administrators with action learning skills because action learning presents a plausible approach for solving complex problems.

In this study, action learning is construed as the learning that grows as the participant learns to solve problems. The measures of action learning were based on problem identification, problem definition, solution finding and implementation. PBL is defined using three measures, namely reflective practice, self-directed learning and collaboration (Hung, Jonassen and Liu 2006). Therefore, the study was guided by three objectives: to analyse the relationship between reflective practice and action learning; to establish the effect of self-directed learning on action learning; to examine the effect of collaboration on action learning. Three hypotheses were developed for the study: there is a relationship between reflective practice and action learning; there is a relationship between self-directed learning and action learning; and there is a relationship between collaboration and action learning.

\section{Reflective practice and action learning}

Reflective practice is a problem-based learning approach, which enables practitioners to become more skilful and more effective (Osterman, 1990), hence, reflective practice involves the idea of integrating theory and practice (Thompson and Pascal, 2012). It is also closely related to the idea of learning from experience. Schon (1983) who greatly influenced the reflective practice theory refers to reflective practice as reflection on action and reflection in action, while Trehan and Pedler (2011) contend that for reflective practice to be effective it must be socially situated, relational and a collective process. Trehan and Pedler's (2011) argument implies that engaging in 
reflective practice that is organisationally situated captures the long standing value of learning from experience of work and working with others which conforms to the principles of action learning.

Thompson and Pascal (2012) observe that while there has been much discussion about theoretical concerns in relation to reflective practice, a considerable confusion among practitioners about what reflective practice entails persists. A review of literature reveals a wealth of theory on reflective practice; however, few empirical studies relating to reflective practice and action learning have been documented. Raelin (2001) and Vince (2002) cited in Reynolds (2011) have developed the theory and practice of reflection that emphasises collective activities hence supporting action learning. Furthermore, a report by Skills for Care (2014) presents 15 case studies by social workers, where it was established that reflective practice enhances a problem solving culture. Since there is a relationship between problem solving and action learning, as earlier noted, we can hypothesise ${ }^{5}$ that:

$H_{1}$. There is a relationship between reflective practice and action learning.

\section{Self-directed learning and action learning}

Knowles (1975: 18) describes self-directed learning as:

A process in which individuals take initiative, with or without the help of others, in diagnosing their learning needs, formulating learning goals, identifying human and material resources for learning, choosing and implementing appropriate learning strategies, and evaluating learning outcomes.

According to Knowles (1975), an individual takes lead for his/her learning. The learner is required to travel some extra miles to gain knowledge, skills or understand of issues (Read, 2001).

Due to benefits of self-directed learning, school environments and corporate settings strongly emphasise the importance of self-directed learning, including its value as a required skill needed for work in the $21^{\text {st }}$ century (Guglielmino, 2013). Guglielmino (2013) argues that today's rapidly changing and increasingly complex environment creates an urgent need for self-directed learning not only for children, but also for adults in the workplace. Literature reveals that most research on self-directed learning has focused on higher education environments (Chakravarthi and Vijayan, 2010). However, self-directed learning is not only relevant in institutions of formal education, but also in organisations and other work environments.

Empirical review reveals that self-directed learning has been associated with high levels of creativity and problem-solving ability (Guglielmino, 2013). Performers who

\footnotetext{
${ }^{5}$ The three hypotheses are denoted as $H_{1} H_{2}$ and $H_{3}$ respectively
} 
scored high on a self-directed readiness scale had jobs that required a high degree of change, high levels of creativity or problem solving skills. Roberts (1986) and Durr (1992) established that self-direct learning readiness scores for managers were higher compared to non-managers. This implies that because managers engage in problemsolving, they develop problem-solving skills such as critical thinking, reflection, selfevaluation, creativity and problem solving. Basing on the documented research where self-directed learning has been associated with reflection, critical thinking and problem solving, we can infer that there is a relationship between self-directed leaning and action learning because action learning is related to problem solving, reflection and critical thinking (Marquardt, 2004).

\section{$H_{2 .}$ There is a relationship between self-directed learning and action learning}

\section{Collaboration and action learning}

Collaboration is an essential element of problem-based learning. Collaboration involves grouping, interdependency, network support and individual accountability whereby each member has to contribute and is willing to learn (Dooly, 2008). For the purpose of this study, collaboration refers to cooperation that would enhance learning. Collaborative learning requires working together towards a common goal and allows learners to actively exchange, debate and negotiate ideas within their groups, thus increasing the individual's interest in learning (Dooly, 2008).

Learners under PBL engage in cooperative group discussions and take responsibility for their learning, which encourages them to become critical thinkers (Totten et al, 1991); critical thinking supports action learning. Action learning is built on the principles of reflection and insightful questioning (Trehan and Pedler, 2011), which are developed during the group debates. Many researchers have reported that students working in small groups tend to debate ideas; therefore, learn more and solve problems (Lohman and Finkelstein, 2000). Grouping promotes action learning, for action learning is the learning that involves group processing (Marquardt, 2004) intended to solve problems and to learn.

Collaborative learning involves an element of individual accountability (Dooly, 2008) which promotes action learning. Dooly's (2008) assertion supports Weinstein (1999) who noted that action learning is individualistic although it follows group agreements, while Bwegyeme and Munene's (2015) research confirmed that under the action learning approach the responsibility of learning rests on the individual.

Literature reveals that group processing and cooperation has been found to be essential for problem solving. Fawsett and Garton (2005) established that collaborative learning enhances problem solving ability among learners. Similarly, Putnam (2000) notes that a group that can cooperate solves the most complex problems but individual accountability is important. Since literature indicates that 
there is a relationship between problem solving and action learning, it can be hypothesised that:

\section{$H_{3:}$ That there is a relationship between group collaboration and action learning.}

\section{Research methodology}

\section{Research design}

We employed both qualitative and quantitative approaches in a quasi-experimental design. Using this design, we carried out an intervention in four Ugandan universities in the departments of the academic registrar. The population included participants from two chartered private universities and two public universities. The universities were purposively selected because they were chartered and the oldest in Uganda; hence, they fulfilled the requirements of the National Council of Higher Education. The quasi experiment was employed in order to try to isolate the influence of real life problem solving on action learning. Review of literature revealed that most action learning studies had been case studies and qualitative (O'Neil and Marsick, 2007; Cho and Egan, 2009); therefore, a quasi-experimental study with a quantitative dimension would add a new aspect to action learning research. The study was done in twelve months and in every six months two universities were studied concurrently. Data was collected at two intervals, that is, period one $\left(\mathrm{P}_{\mathrm{O}}\right)$ which served as the baseline and period two $\left(\mathrm{P}_{1}\right)$. Various techniques were utilised in order to overcome the inherent limitation in each of the methodologies when used alone.

\section{The study population and sampling}

The population was composed of all the faculty administrators, assistant registrars and senior registrars in the Universities, totalling 191. The population was made of four universities, which have been coded as A, B, C and D. University A had 27 participants, University B had 26 participants, University C had 47 participants and university D had 91 participants. University A had 1 deputy registrar, 2 senior registrars, 24 Assistant registrars; while University B had 1 deputy registrar, 2 senior registrars and 23 Assistant registrars. University $C$ had 2 deputy registrars, 25 senior registrars and 20 Assistant registrars; while University D had 4 deputy registrars, 35 senior registrars and 52 Assistant registrars. The Krejcie and Morgan (1970) method of sample size determination was employed. Disproportionate stratified sampling was used whereby the sample drawn from each university depended on its population. Out of a population of 191, a sample size of 123 was drawn. Approximately 110 administrators participated at the pre-test stage; however, 103 were able to complete the experiment. Simple random sampling was employed in order to minimise selection bias. To get the simple random sample, we employed the Fishbowl draw method 
(Moore, 2010) where all the names of the population were listed and we picked 168 irrespective of positions, hence every administrator in the academic registrar's office had an equal chance of being picked.

The sample size comprised of the action-learning group, the traditional didactic learning group and the control group. The control and the traditional didactic groups were employed to minimise the Hawthorne effect. The Hawthorne effect refers to inclination of some people to work harder and perform better when they are being observed as part of the experiment (Mayo, 1949). This study being a quasi-experiment we had to manage this effect because all the three groups were in the same environment. The action-learning group was composed of sets of eight members each who were randomly selected to allow experiential diversity as recommended by O'Neil and Marsick (2007). The action learning sets were trained using the action learning principles while the traditional didactic learning group was trained using the traditional lecture method. The control group was not trained. This article establishes the differences among the learning groups before and after training. The article further discusses the relationship between problem-based learning and action learning, focusing on the action-learning group.

\section{The intervention}

The intervention was designed according to the Marquardt (2004) and O'Neil and Marsick (2007) models of action learning hence action learning was paired with short classes and situated activities in order to create an interest in learning which would, inspire change. The Marquardt model has six essential elements, which include the problem, the action learning set, questioning and reflection, commitment to learn, action and the coach. The power of action learning is at its peak when all the six are in operation (Marquardt, 2004). The O'Neil and Marsick model allows for incorporation of just-in-time programmed classes.

The action learning sets identified specific problems to solve in their area of jurisdiction after which they laid down ground rules that guided their meetings and operations. A communication platform was created and an environment of a community of practice was created where action learning-set members interacted regularly. A set leader was chosen to coordinate all activities of the set. The set leader was the problem owner and was accountable for the progress.

The training manual was designed according to the constructivist learning theories and action learning theory. The learning theories encompassed; Community of practice, Situated learning, Experiential learning, Problem-based learning, and Discovery learning. This article, however, purposes to highlight the effect of problembased learning on action learning, hence, the article is quiet about other theories. Action learning principles were clearly highlighted to the participants by the coach and the facilitators in line with the training manual. Questioning and reflection approaches were utilised by the participants while the coach guided them through the 
process of problem solving. The researcher captured data through observation, questionnaires and evaluation forms.

At the commencement of the training $\left(\mathrm{P}_{0}\right)$, we gave out the self-administered questionnaires and evaluation forms to all the participants in the experiment, in order to establish the base line. After $\left(\mathrm{P}_{0}\right)$, identical questionnaires and evaluation forms were re- administered to the participants to help establish the difference between the groups and among the groups at $\left(\mathrm{P}_{1}\right)$. Seven action-learning sets of eight participants each, met fortnightly to share learning experiences and pool their knowledge. The action learning sets analysed and discussed problems during informal and formal meetings to devise solutions to the identified problems.

\section{The measures of the variables, validity and reliability of the instrument}

The constructs were measured using a six- point scale. The study involved small numbers of respondents, hence, Partial Least Squares Path Modeling (PLSPM) was found to be appropriate to confirm the validity and reliability of the instrument and to establish the significance of the relationships.

Variables of problem-based learning included reflective practice, self-directed learning and collaboration. Reflective practice was measured with 4 items developed from literature (Hung, Jonassen and Liu, 2006; Thompson and Pascal, 2012). Collaboration was measured with four items developed from Hung, Jonassen and Liu's (2006) study, while self-directed learning was measured with four items developed from Guglielmino (2013). Action learning was measured by 16 items under the dimensions of decision-making, problem definition, generation of alternatives and solution selection. The action learning measure was developed according to the problem solving process framework established by D'Zurilla, Nezu and MaydeuOlivares (2004). The problem solving process was used to measure action learning because the review of literature reveals that action learning is the learning that results from the process of problem solving (McGill and Brockbank, 2004).

To assess the measurement models, the factor loadings, composite reliability and Average Variance Extracted (AVE) were taken into consideration. All the item loadings for the variables were all higher than .7 as recommended by Glocker (2012). The composite reliability (Cronbach Alpha) as a measure of reliability was higher than .7 as recommended by Cronbach (1951). The Average Variance Extracted (AVE) was higher than .6 as recommended by Sanchez (2013). All the manifest variables adequately represented the latent variables used in the study (Appendix table 4 and 5).

\section{Data collection and analysis}

Quantitative data was collected by using questionnaires and the qualitative data from observation notes; evaluation forms filled in by the respondents enriched the study findings. In order to compare action learning and traditional training approach, 
Analysis Of Variance (ANOVA) was employed and the differences among the three groups, namely the action-learning group, the traditional learning group and the control were established. Pearson product moment correlation was carried out to check whether the problem-based learning variables were positively and significantly correlated to action learning. Thereafter, a hierarchical regression analysis was conducted to assess the predictive power of the problem-based learning variables (independent variable) towards action learning (dependent variable). 
Table 1: The differences in the groups

\begin{tabular}{|c|c|c|c|c|c|c|c|c|c|}
\hline \multirow[t]{2}{*}{ Variable } & \multirow[t]{2}{*}{ Learning group } & \multicolumn{4}{|c|}{ Period } & \multicolumn{4}{|c|}{2 Period } \\
\hline & & $\mathbf{N}$ & Mean & $\begin{array}{c}\text { Std. } \\
\text { Deviation }\end{array}$ & Sig & $\mathbf{N}$ & Mean & $\begin{array}{c}\text { Std. } \\
\text { Deviation }\end{array}$ & Sig \\
\hline \multirow[b]{2}{*}{$\begin{array}{l}\text { Community } \\
\text { of practice }\end{array}$} & Action learning & 44 & 3.73 & .59 & \multirow[b]{2}{*}{0.361} & 43 & 4.23 & .57 & \multirow[b]{2}{*}{0.005} \\
\hline & $\begin{array}{l}\text { traditional learning } \\
\text { control group } \\
\text { Total }\end{array}$ & $\begin{array}{l}39 \\
27 \\
110 \\
\end{array}$ & $\begin{array}{l}3.56 \\
3.52 \\
3.62 \\
\end{array}$ & $\begin{array}{l}.68 \\
.75 \\
.66 \\
\end{array}$ & & $\begin{array}{l}32 \\
28 \\
103 \\
\end{array}$ & $\begin{array}{l}3.78 \\
3.75 \\
3.96 \\
\end{array}$ & $\begin{array}{l}.79 \\
.75 \\
.73 \\
\end{array}$ & \\
\hline \multirow{5}{*}{$\begin{array}{l}\text { Situated } \\
\text { learning }\end{array}$} & Action learning & 44 & 4.25 & .76 & \multirow{4}{*}{0.564} & 43 & 4.72 & .76 & \multirow{4}{*}{0.029} \\
\hline & traditional learning & 39 & 4.07 & .76 & & 32 & 4.42 & .66 & \\
\hline & control group & 27 & 4.22 & .93 & & 28 & 4.30 & .53 & \\
\hline & $\begin{array}{l}\text { Total } \\
\text { Action learning }\end{array}$ & 110 & 4.18 & .80 & & 103 & 4.51 & .69 & \\
\hline & Action learning & 44 & 4.45 & .57 & & 43 & 4.78 & .58 & \multirow{4}{*}{0.001} \\
\hline \multirow{3}{*}{$\begin{array}{l}\text { Discovery } \\
\text { learning }\end{array}$} & traditional learning & 39 & 4.30 & .67 & \multirow{3}{*}{0.206} & 32 & 4.49 & .59 & \\
\hline & control group & 27 & 4.57 & .56 & & 28 & 4.23 & .58 & \\
\hline & Total & 110 & 4.42 & .61 & & 103 & 4.54 & .62 & \\
\hline \multirow{4}{*}{$\begin{array}{l}\text { Problem } \\
\text { based } \\
\text { learning }\end{array}$} & Action learning & 44 & 4.20 & .51 & \multirow{4}{*}{0.334} & 43 & 4.58 & .58 & \multirow{4}{*}{0.004} \\
\hline & traditional learning & 39 & 4.13 & .77 & & 32 & 4.31 & .59 & \\
\hline & control group & 27 & 4.37 & .69 & & 28 & 4.07 & .72 & \\
\hline & Total & 110 & 4.21 & .66 & & 103 & 4.36 & .65 & \\
\hline \multirow{4}{*}{$\begin{array}{l}\text { Experiential } \\
\text { learning }\end{array}$} & Action learning & 44 & 4.70 & .67 & \multirow{4}{*}{0.950} & 43 & 4.88 & .70 & \multirow{4}{*}{0.002} \\
\hline & traditional learning & 39 & 4.36 & .81 & & 32 & 4.63 & .71 & \\
\hline & control group & 27 & 4.63 & .74 & & 28 & 4.25 & .75 & \\
\hline & Total & 110 & 4.56 & .75 & & 103 & 4.63 & .75 & \\
\hline & Action learning & 44 & 4.43 & .70 & \multirow{4}{*}{0.690} & 43 & 4.53 & .55 & \multirow{4}{*}{0.018} \\
\hline Action & traditional learning & 39 & 4.36 & .77 & & 32 & 4.38 & .71 & \\
\hline \multirow{2}{*}{ Learning } & Control group & 27 & 4.51 & .75 & & 28 & 4.11 & .57 & \\
\hline & Total & 110 & 4.42 & .74 & & 103 & 4.37 & .63 & \\
\hline
\end{tabular}

\section{Source: Field data, 2016}




\section{Results}

In Table 1 One way ANOVA was used to determine whether there are any statistically significant differences between the means of the three independent groups. In the first section, the groups were compared before the training (period one). The means measure the average responses of the experimental groups resulting from the items that measure a particular variable. The ANOVA results indicate that there was no specific pattern of mean distribution among the groups. For example, the results indicate that for the variable of community of practice, the action-learning group had the highest mean and the control group had the lowest; while for discovery learning, the control group had the highest mean and traditional learning group had the lowest mean. It was observed that all the means of the groups were not significantly different, the P-value was greater than 0.05 . The P-value for community of practice is 0.361 , which is $>0.05$, situated learning is 0.564 , which is $>0.05$, discovery learning is 0.206 , which is $>0.05$, problem based learning is 0.334 , which is $>0.05$, experiential learning is 0.950 , which is $>0.05$, and action learning is 0.690 which is also $>0.05$. It can be deduced that there was no significant difference among the three groups before action learning training. The second section of Table 1 displays significant differences among the groups in the second period. The mean of the action-learning group was higher than that of the traditional learning and control groups for all the variables. The P-values for the variables of community of practice, situated learning, discovery learning, problem-based learning, experiential learning and action learning was less than 0.05 , which indicates significant differences among the groups. This means that participants in the action-learning group improved more in their responses than other groups after the training, which was an indicator that their performance in different areas was better. The results affirm that action learning is an effective method of training when compared to the traditional training method.

Table 2: Correlations between the problem-based learning indicators and action learning

\begin{tabular}{lccccccc}
\hline \multicolumn{1}{c}{ Variable } & 1 & 2 & 3 & 4 & Mean & SD & $\begin{array}{c}\text { Cronbach } \\
\text { Alpha }\end{array}$ \\
\hline Reflective practice & 1 & & & & 4.0 & 0.88 & 0.84 \\
Self-directed learning & $0.44^{* *}$ & 1 & & 4.7 & 0.76 & 0.74 \\
Collaboration & $0.23^{*}$ & $0.31^{* *}$ & 1 & 4.3 & 0.63 & 0.86 \\
Action learning & $0.53^{* *}$ & $0.50^{* *}$ & $0.22^{*}$ & & 4.3 & 0.80 & 0.77 \\
\hline
\end{tabular}

${ }^{*}$ correlation significant at 0.05 (2 tailed)

${ }^{* *}$ correlation significant at 0.01 (2 tailed)

Source: Field data, 2016 
After comparing the action learning approach with the traditional learning approach, the correlations and regression were done. Correlations were employed to establish the relationship between problem-based learning constructs and action learning among the action-learning group while regressions were done to establish the predictive power of the independent variables on the dependent. Table 2 presents descriptive statistics and the correlations among the study variables while Table 3 presents the regression model. The descriptive statistics in table 2 indicate that all the variables of the study scored above scale mean. Action learning $(\mathrm{M}=4.3, \mathrm{SD}=0.80)$, reflective practice $(\mathrm{M}=4.0, \mathrm{SD}=0.88)$, self-directed learning $(\mathrm{M}=4.7, \mathrm{SD}=0.88)$, collaboration $(\mathrm{M}=4.3, \mathrm{SD}=0.63)$. The findings show that all the variables had a mean above 4 , which implies that the majority of respondents agreed with the descriptive items in the questionnaire, since we employed a six scale, Likert questionnaire. The standard deviations were all small because they were below one, an indicator that most of the data clustered around the mean; therefore, the mean is a true representation of the data in the study.

Table 3: Hierarchical regression analysis of reflective practice, self-directed learning, collaboration and action learning

\begin{tabular}{|c|c|c|c|}
\hline Predictor variable & $\begin{array}{c}\text { Model } 1 \\
\text { B }\end{array}$ & $\begin{array}{c}\text { Model } 2 \\
\beta\end{array}$ & $\begin{array}{c}\text { Model } 3 \\
\text { B }\end{array}$ \\
\hline Reflective practice & $0.43^{*}$ & $.31^{*}$ & $0.31^{\star \star}$ \\
\hline Self-directed learning & & $.30^{\star *}$ & $0.31^{* *}$ \\
\hline Collaboration & & & -0.02 \\
\hline $\mathrm{R}^{2}$ & $.29^{* *}$ & $.39 * *$ & $0.39^{* *}$ \\
\hline $\mathrm{R}^{2}$ (Adjusted $)$ & $.25^{\star *}$ & $.35^{\star *}$ & $0.35^{\star *}$ \\
\hline Change $R^{2}$ & $.28^{\star *}$ & $.10^{\star *}$ & 0.00 \\
\hline $\mathrm{F}$ & $8.04^{* *}$ & $10.33^{* *}$ & $8.78^{* *}$ \\
\hline Change $\mathrm{F}$ & $39.03^{* *}$ & $15.69^{* *}$ & 0.07 \\
\hline
\end{tabular}

Dependent variable: action learning

Source: Field data, 2016

The demographic variables of age range, educational level and years of service were controlled for and found to be statistically insignificant with regard to their prediction of action learning. Therefore, they are not presented in the model. $H_{l}$ stated that there is a positive significant relationship between reflective practice and action learning. The findings in Table 2 indicate a positive significant correlation between reflective practice and action learning $(\mathrm{r}=.53, \mathrm{p} \leq .01)$, implying that there is a positive association between reflective practice and action learning. The hierarchical regression test in table 3 , further supported $H_{l}$, reflective practice significantly predicted action learning. In table 3 , model 1 reflective practice was introduced and the results indicated that the predictive power of the model was statistically significant $(\beta=0.43$, $\mathrm{R}^{2}=0.29, \mathrm{R}^{2}$ adjusted $=0.25$, change in $\mathrm{R}^{2}=0.28$ and $\mathrm{F}$-statistic $=8.04, \mathrm{P}=0.01$ ). The $\beta$ value indicates that for every one-unit increase in reflective practice, action-learning 
increases by the unstandardised $\beta$ coefficient value (0.43). With the introduction of reflective practice, model 1 explained $25 \%$ of the variance in action learning, which is statistically significant. In model 1 , the $25 \%$ variance in action learning could be attributed to reflective practice.

$\mathrm{H}_{2}$ stated that there is a significant positive relationship between self-directed learning and action learning. The results in Table 2 indicated a significant correlation between self-directed learning and action learning $(\mathrm{r}=.50, \mathrm{p} \leq 0.01)$ implying that there is a positive association between self-directed learning and action learning, when there is improvement in self-directed learning action learning improves. $\mathrm{H}_{2}$ was further supported in the hierarchical model 2 , in table 3 . When self-directed learning was introduced to the model, the results indicated that the model predictive power increased $(\beta$ value for reflective practice $=0.31, \beta$ value for self-directed learning $=0.30, R^{2}=0.39, R^{2}$ adjusted $=0.35$ while change $R^{2}$ is 0.10 which were all statistically significant. The F-statistic $=10.33$ while $\mathrm{P}=0.01$, which further indicate the model's predictive power. The model accounts for $35 \%$ of the variation in action learning, representing an increase from $25 \%$ in model 1 to $35 \%$ whereby self-directed learning accounts for $10 \%$ (change in $\mathrm{R}^{2}$ ), which is statistically significant.

$\mathrm{H}_{3}$ hypothesised that there is a positive significant relationship between collaboration and action learning. The Pearson results in Table 2 reflect a weak, significant correlation between collaboration and action learning $(r=.22, p \leq 0.05)$. To determine the predictive power of collaboration, collaboration was introduced in the hierarchical regression model 3, (Table 3). When collaboration was introduced to the model, the percentage variance explained ( $\mathrm{R}^{2}$ adjusted) remained unchanged at 0.35 as in model 2, change $R^{2}$ was $0.00, \beta$ value for reflective practice $=0.31, \beta$ value for selfdirected learning $=0.31$, and $\beta$ value for collaboration $=-0.02$. The $\beta$ values for selfdirected learning and reflective practice were significant while the collaboration $\beta$ value was insignificant. F-statistic was 8.78 while $\mathrm{t}$-value was -0.27 which was insignificant and $\mathrm{P}=0.79$ which $>0.01$. Therefore, model 4 was statistically insignificant and the hypothesis was thus rejected.

The results in Table 3 indicate that model 2 provided a best model that fits with higher predictive power. In addition, the results emphasise the robust strength of reflective practice of the three variables. The Durbin-Watson results is 2.009 indicating that the analysis meets the assumption of independent errors as recommended by Field (2009) who observes that when the Durbin-Watson results are closer to 2 the assumption of independent errors will be fulfilled.

\section{Discussion of findings}

This article aimed at establishing the relationship between problem-based learning constructs and action learning. The first objective was to establish the effect of reflective practice on action learning. In order to achieve the first objective, a hypothesis was stated and tested, a correlation run and then a hierarchical regression 
was done. $H_{l}$ stated that there is a significant relationship between reflective practice and action learning. The findings from the Pearson correlations indicate a positive significant relationship between reflective practice and action learning as hypothesised. In addition, the regression indicated a significant predictive capacity of reflective practice, which implies that enhancement of reflective practice skills boosts action learning. This finding is in agreement with previous studies (McGill and Brockbank, 2004; Skills for Care Report, 2014), which affirm that reflective practice enhances action learning through improving problem solving skills. This study established that reflective practice activities entailed regular contemplation on the next course of action, periodically reflecting on one's experiences and actions, keeping a journal, learning from mistakes, trying to understand others and exercising active listening during communication (Appendix Table 4). The responses from the administrators indicate that they regularly engaged in reflection. This was further supported by qualitative findings from the evaluation forms and observation where administrators stated that they regularly reflected on their work, kept diaries and devised better ways of dealing with challenges. The finding is consistent with Schon's (1983) theory of reflective action, in which he observes that practitioners can reflect on behaviour either as it happens, or reflect on action after the event to review, analyse, and evaluate the situation. As a result, the practitioner uses intuition to analyse and evaluate the circumstances with the intention of addressing challenges.

The findings in Table 3 demonstrate the robust strength of reflective practice as a predictor of action learning which is consistent with Osterman (1990). Osterman (1990) observes that while the experience of a practitioner may serve as the stimulus for learning, reflection is the essential part of the process that makes it possible to learn from experience, because without reflective practice, theories of action will not be revised and learning will not occur. In a work place context, the experienced employees use reflective practice to inquire and understand what may have been overlooked in practice as articulated by Osterman (1990). Through reflective practice, the administrators were able to contemplate about the problems, inquire into their experiences, and subsequently unearth and reframe the problems to find solutions and make decisions. As they solved their respective problems, action learning occurred.

The second objective was to establish the effect of self-directed learning on action learning. To achieve this objective, a hypothesis was developed and tested using Pearson correlation and a regression was run to test the predictive power. $H_{2}$ stated that there is a significant relationship between self-directed learning and action learning. The findings demonstrated that self-directed learning was positively and significantly related to action learning, which is supported by extant research (Patterson et al, 2002; Guglielmino, 2013). The findings imply that as the employees' skills in self-directed learning improve, there is more of action learning. Guglielmino (2013) established that performers who scored high on a self-directed readiness scale had jobs that required high levels of creativity and problem solving skills. This implies that employees who engage in problem-solving, develop problem-solving skills hence 
action learning. The faculty administrators' job demands problem solving skills and creativity to serve the big numbers of students and academic staff in the universities amidst scarcity of resources. Consequently, the faculty administrators have to acquire self-directed learning skills in order to cope with the challenging responsibilities. This finding demonstrates that as the administrators got the principles of self-directed learning, they were better in directing their own learning and, hence, improved in action learning. Because of the self-directed learning skills, the administrators developed self-initiative and were responsible for their learning, which affirms Clardy's (2000) assertion that self-directed learning brings self-initiativeness and allows the learner to diagnose his learning needs.

The third objective was to examine the effect of collaboration on action learning. This objective was achieved by running a correlation and a regression. $H_{3}$ stated that there is a significant relationship between collaboration and action learning. The Pearson's correlation result in Table I indicates a weak relationship between collaboration and action learning. In order to establish the predictive power of collaboration, a hierarchical regression was run. However, the hierarchical model results in Table 3 reveal an insignificant statistical predictive power of collaboration to action learning, hence, hypothesis 3 was rejected. This finding is worth pursuing further to establish whether collaboration is important during action learning or not. Some researches like Weinstein (1999) and Bwegyeme and Munene (2015) have observed that action learning is very individual although it follows group agreements and a great deal of it cannot be anticipated, which implies that it is difficult to manipulate action learning results because the onus of learning rests on the learner.

In addition, the findings are in agreement with the theory of problem-based learning, which states that important problems are the anchor of learning as articulated by Dewy (1916) and Hung, Jonassen and Liu (2006). Each action learning set identified a problem that motivated them to learn as they devised a solution to the problem, which is in agreement with previous problem based learning research. However, the driving force was mainly reflective practice, because problems were existing before the training but effective effort to solve them was not applied.

\section{Conclusions}

The purpose of the study was to establish the relationship between problem-based learning and action learning. Specifically, the study addressed the relationship between reflective practice, self-directed learning, collaboration, and action learning. The literature reviewed confirmed the relationships as hypothesised. The research confirmed that reflective practice and self-directed learning were strong predictors of action learning while collaboration was not. The results have demonstrated that problem-based learning (reflective practice and self-directed learning skills) are essential for workplace learning, which is action oriented. 


\section{Practical implications}

The results have demonstrated the robust strength of reflective practice as a predictor of action learning. More to that, the study clarifies through empirical research what reflective practice entails. The findings can be utilised to design future training programmes in universities and other workplaces to equip workers with reflective practice and self-directed learning skills that are vital in solving workplace problems. Organisations should recognise the central role of reflective practice in action learning, hence, regular individual and group reflections should be encouraged to develop analytical and critical thinking skills that are important for workplace learning.

Most of the extant empirical research links problem-based learning to problemsolving, but this study links problem-based learning to action learning. Therefore, the study highlights the relevance of problem-based learning when employing the action learning approach. The findings point to the need to introduce problem-based learning in various disciplines at different educational levels in Uganda and other countries. Problem-based learning prepares the students in higher education for the workplace environment.

\section{Limitations and areas for further research}

This study was a quasi-experiment, correlational and majorly quantitative. However, for better explanation of how problem-based learning impacts action learning, an intervention with a longitudinal design would be more appropriate. Further studies relating collaboration and action learning should be carried out. The research focused on administrators in the academic registrar's department, future researchers could focus on managers and other administrators in organisations that require critical thinking and problem solving skills, other than universities.

\section{References}

Alvarstein, V., and Johannesen, L. K., 2001. Problem-based learning approach in teaching lower level logistics and transportation. International Journal of Physical Distribution and Logistics Management Vol. 31 (7/8): 557-573.

Anderson, L. W. and Krathwohl, D. R., 2001. A taxonomy for learning, teaching and assessing. A revision of Bloom's taxonomy of educational objectives, New York: Longman.

Bigabwenkya, S., 2013. Public University Education: An analysis of capability expansion among students in Uganda. $\mathrm{PhD}$ dissertation, University of South Africa. 
Bwegyeme, J., and Munene, J. C., 2015. "Action learning the tool for problem solving in Universities; Uganda Martyrs Nkozi, Makerere and Nkumba Universities." Action Learning: Research and Practice Vol. 12(1): 54-64

Boshyk, Y. 2002. Action learning worldwide: Experiences of leadership and organisational development. London: Palgrave-Macmillan.

Chakravarthi, S., and P. Vijayan, P., 2010. Analysis of psychological impact of problem-based learning (PBL) towards self-directed learning among students in undergraduate medical education. International Journal of psychological studies, 2 (1): 38-43.

Cho, Y. and Egan, T. M., 2009. Action Learning Research: A Systematic Review and Conceptual Framework. Human Resource Development Review Vol. 8(4) 431-462.

Clardy, A., 2000. "Learners speak out." Training and development journal Vol. 54(4):52-52

Cronbach, J.L., 1951. Coefficient Alpha and the internal structure of Tests. Psychometrika

16: 297-334

Dooly, M. ed., 2008. Tele-collaborative language learning: A guidebook to moderating intercultural collaboration online.

Ddumba Ssentamu, J., 2013. Prospects and Challenges of Higher Education in Uganda. Unpublished paper.

Dewy, J., 1916. Democracy and education. An introduction to the philosophy of education (1966 Edition)

Durr, R. E., (1992). An examination of readiness for self-directed learning and selected personnel variables at a large mid-western electronics development and manufacturing corporation. PhD dissertation, University of Atlantic, Florida.

D'Zurilla, T. J., Nezu, A. M., and Maydeu-Olivares, A., 2004. What is social problem solving? Meaning, models, and measures. In: Social problem solving: Theory, research, and training, Chang, E.C., D'Zurilla, T.J., and Sanna, L.J., (Eds.), Washington, DC, American Psychological Association, 2004, pp. 11-27.

Fawcett, L. M., and Garton, A. L., 2005. The effect of peer collaboration on children's problem solving ability. British Journal of Educational Psychology, 75: 157-169.

Field, A.P., 2009. Discovering statistics using SPSS: and sex and drugs and rock and roll (3rd edition), London: Sage

Gallagher, S. A., Stepien, W. J., and Rosenthal, H., 1992. The effects of problem based learning on problem solving. Gifted Child Vol. 36(4): 195-200.

Glocker, T. J., 2012. Partial Least Squares Path Modelling: Introduction and Application. University of Vaasa. [Online] Available From: http://lipas.uwasa.fi/ tglo/documents/PLS_Path_Modeling.pdf [Accessed 30 November 2014]

Guglielmino, L. M., 2013. The case for promoting self-directed learning in formal educational institutions. SA-eDUC, 10(2) 
Hung, W., Jonassen. , D. H., and Liu, R., 2006. Problem-based learning: A handbook of Research on Educational Communication and technology, $3^{\text {rd }}$ edition. In: Problem-based learning, Merriënboer, M. D., Merrill, and Driscoll, M., (Eds), Mahwah, N. J, Erlbaum, 2006, pp. 485-506

Kiguli-Malwadde, E., Businge, F., and Mubuuke, A., 2009. Attitudes and perceptions of students and teachers about problem-based learning in the radiography curriculum at Makerere University, Uganda. European Journal of Radiography Vol. 1(4):156-162

Knowles, M. S., 1975. Self-directed learning: A guide for learners and teachers. New York: Association Press.

Krejcie, R. and Morgan D. W., 1970. Determining the sample size for research activities. Educational and psychological measurement 30: 607-610

Lohman, M. C., and Finkelstein, M,. 2000. Designing groups in problem-based learning to promote problem solving skills and self-directedness. Instructional Science, 28:291-307, doi: 10.1023/A: 1003927228005

Maister, D., 2014. Why training is useless. [Online] Available From: http://davidmaister.com/why-training-is-useless/ [Accessed 22 April 2014]

Makerere University, 2009. Human Resources Manual. [Online] Available From: http://policies.mak.ac.ug/sites/default/files/policies/Human-resources-manualpdf [Accessed $1^{\text {st }}$ June 2015]

Marquardt, M. J., 2004. Optimizing the power of action learning, solving problems and building leaders in real time, California: Davies-Black publishing.

Mayo, E. 1949. Hawthorne and the western electric company. Public administration: concepts and cases, 149-158

McGill, I., and Brockbank, A., (Eds), 2004. The action-learning handbook. Powerful techniques for educational, professional development and training. New York, USA: Routledge

Moore, D. S., 2010. The basic practice of statistics. Palgrave, Macmillan.

Nabayego, C. and Itaaga, N., 2014. How university education in Uganda can be improved to prepare economically productive graduates. .Asian journal of social sciences and management studies, Vol. 1(2): 62-70

O’Neil, J., and Marsick, V.J., 2007. Understanding action learning, New York: AMACOM

Osterman, K. F., 1990. "Reflective Practice: A new agenda for education. Education and urban society, Vol. 22(2): 133-152.

Patterson, C., Crooks, D., and Lunyk-Child, O., 2002. A new perspective on competences for self-directed learning. Journal of nursing education, Vol. 41(1): 25-31.

Putnam, R., 2000. Bowling alone. New York: Simon \& Schuster.

Raelin, J. A., 2002. I don't have time to think! Versus the art of reflective practice.

Reflections, Vol. 4(1): 66-79.

Read, J. M., 2001. Developing self-directed learning. Research and practice in human 
resource management, Vol. 9(1):119-137.

Revans, R. W., 1980. Action learning: New techniques for management. London: Blond \& Briggs.

Reynolds, M. 2011. Reflective practice: Origins and interpretations. Action learning: research and practice 8(1): 5-13

Roberts, D. G., 1986. A study of the use of the self-directed learning; Readiness scale as related to selected organizational variables. A PhD dissertation, George Washington University.

Sanchez, G., 2013. PLS Path Modelling with R, Trowchez Editions, Berkeley. [Online] Available From: https://www.gastonsanchez.com/PLS_Path_Modeling_with_R.pdf [Accessed 15 November 2014]

Schon, D., 1983. The reflective practitioner. How professionals think in action. New York: Basic Books

Silverman, R., 2012. So much training, so little to show for it. An expert on corporate programs reveals why they often are a waste of time and money. The wall Street journal, 26 October 2012. [Online] Available From: https://www.wsj.com/articles/SB1000142405297020442590457807295051855832 8 [Accessed 18 June 2013]

Skills for Care. 2014. Critically reflective action learning: Improving social work practice through critically reflective action learning. [Online] Available From: www.skillsforcare.org.uk [Accessed 28 January 2015]

Thompson, N. and Pascal, J., 2012. Developing critically reflective practice, reflective practice; International and multidisciplinary perspectives. Reflective Practice Journal, Vol. 13(2):311-325.

Tibarimbasa, A., (2010). Factors affecting the management of private universities in Uganda. (Unpublished). A PhD dissertation, Thesis in education management, Makerere University, Kampala Uganda

Totten, S., Sill, T., Digby, A., and Russ, P., 1991. Cooperative learning: A guide to research. New York: Garland

Trehan, K., and Pedler, M., 2011. Action learning and its impact. Action Learning; Research and Practice, Vol. 8 (3): 183-186

Walker, D., and Myrick, F., 2006. Grounded Theory: An exploration of process and procedure. Qualitative Health Research, Vol. 16 (4): 547-559

Weinstein, K., 1999. Action learning. A practical guide. England: Gower 


\section{APPENDIX}

Table 4: Problem-based learning measurement

\begin{tabular}{|c|c|c|c|}
\hline Latent Variable \& Manifestations & Item loadings & AVE & Cronbach \\
\hline \multicolumn{4}{|l|}{ Reflective practice } \\
\hline $\begin{array}{l}\text { When faced with challenging work assignments, I take time off to think } \\
\text { about the next Course of action. }\end{array}$ & .75 & & \\
\hline At the end of each meeting, I take time to reflect on my actions. & .82 & & \\
\hline $\begin{array}{l}\text { When a person is talking to me I try to understand him by putting } \\
\text { Myself in his shoes. }\end{array}$ & .79 & & \\
\hline $\begin{array}{l}\text { I always try to actively listen to the speaker by showing responses e.g. } \\
\text { nodding the head, asking questions etc. }\end{array}$ & .75 & .60 & .84 \\
\hline I always learn from mistakes & .74 & & \\
\hline
\end{tabular}

\section{Self- directness}

I do keep a diary $\quad .77$

I do question while seeking clarity and fresh insight into what I do not know.

When I learn something from the work environment, I do not easily forget it. .93

$\begin{array}{lll}93 & .67 & .74\end{array}$

I am fully responsible for my learning and problem solving

If there is something that I want to learn, I can figure out a way to learn it.

\section{Collaboration}

There is cooperation in the department as we execute our duties.

My peers and I in the department freely share relevant information.

I am proud of being part of this department

In this department, we trust each other.

Source: Field data, 2016 
Table 5: Action learning measurements

Cronbach

\title{
Decision implementation
}

When solving a problem I prioritise the solutions into what would work best.

I always revise the solution to the problem if it does not work as expected.

If the selected solution to a problem is too hard to implement or it is just not working , I $\quad .79$

revise it or try something else

Usually I monitor the effects of the alternative solution I have decided to implement. $\quad .79$

I always ensure that I implement the selected alternative whole-heartedly

.75

\section{Problem definition}

I always make sure that I establish the actual problem

I normally establish the causes and effects of a problem

.84

I am able to define realistic objectives regarding the problem I am trying to solve

.83

When I am defining the problem, I always think about how the current situation is different $\quad .84$ from how I would like it to be.

Whenever I am faced with a problem to solve, I identify obstacles.

\author{
.56
}

.63

\section{Generation of alternatives}

Before I tackle a problem, I try to clearly understand the nature of the problem.

.91

If my attempts to solve a particular problem in the past have been futile, I generate other .85 solutions that may work better.

As a department, we usually brainstorm to generate several alternative solutions to a .61

\section{Selecting a solution}

Whenever attempting to find a solution to a problem I think of various ways to approach the $\quad .68$ problem.

I always ask myself what solution I employed for a similar problem in the past and how 0.84 effective was that solution.

In selecting a solution to a problem, I examine all possible options to make the best choice.

0.85

0.63

Source: Fielddata, 2016 


\section{Author Biographies}

Jacinta Bwegyeme (PhD) holds a doctorate in human resource management and currently is a senior lecturer in human resource management and other management courses at Uganda Martyrs University. She has research interests in action learning and human resource Management.

John .C. Munene (PhD) is a professor of industrial/organisational psychology with a focus on organisational development and human resource. He is currently the programme director at the graduate research centre, Makerere University Business School. He is also the lead consultant at PILA Consultants (U). He does research in organisational development, human resource management, and entrepreneurship

James Kagaari (PhD) is an associate professor of psychology at Kyambogo University. He was honoured with a global award of "Fellow" by the International Association of Applied Psychology (IAAP) for his contribution to the growth and development of psychology globally. He does research in psychology.

Geoffrey Bakunda (PhD) is a professor and dean at the faculty of Marketing and Hospitality, Makerere University Business School. He has developed teaching and research skills in the areas of international trade, marketing, strategic management and enterprise development. 